\title{
Information Content of Annual Earnings Announcements: Evidence from Moroccan Stock Market
}

\author{
Dr. Khalid El Ouafa \\ Cadi Ayyad University, PO box 4162, FPD Sidi Bouzid, Safi, Morroco
}

\begin{abstract}
The objective of our work is to study the information content of accounting results of listed companies in the Casablanca Stock Exchange. Applying the methodology adopted by Beaver (1968), we analyze the market reaction, in terms of changes in prices and volumes around the announcement of annual earnings. Our study focuses on 75 companies listed on the Casablanca Stock Exchange for the period [2010 to 2015]. It accounts for the presence of an informational content for the accounting results around the announcement date. Thus, this confirms the hypothesis of financial market efficiency in its semi-strong form (Fama, 1970) and the results obtained in other financial markets (US, French, Chinese ...).
\end{abstract}

Keywords: Information Content, Moroccan Stock Market, Earnings announcements.

\section{Introduction}

Empirical research on accounting and financial information and its relationship with the financial market is relatively a recent activity. Until all the early 70 's, this research was primarily normative and oriented toward a purely theoretical basis, focusing on the accounting methods and conventions. Therefore, the empirical verification of theoretical propositions, existing approach in most sciences, was absent in accounting until the late 60's. The exceeding of normative framework for accounting data is due, first, the development of positive approach (empirical) in economics, then the development of the Capital Asset Pricing Model (CAPM) and finally to the hypothesis of efficiency (in its semi-strong form) of financial markets supported by Fama (1970).

Typically, event studies consist of evaluating the unexpected impact of the announcement of an economic or political event on stock prices. They are based on the central idea that financial markets react immediately to new information which may affect the value of financial stocks. According to Mackinlay (1997), the first dates back to Dolley (1933) who studied market reaction according to the announcement of the allocation of 'Split'. However, this study shows some methodological limitations. It was towards the end of the sixties that Ball and Brown (1968) and Fama, Fisher, Jensen and Roll (FFJR) (1969) provided methodological adjustments based on the market model established by Sharp (1964) and assuming the hypothesis of the efficiency of the financial market. Since then, the event studies have experienced a wide acceptance in corporate finance especially for measuring the market reaction following the announcement of events such as initial public offering (IPOs), funding decisions, the allocation of splits, the accounting or financial measures, strategic alliances, mergers and acquisitions, buyouts, corporate social performance, etc.

Our study is part of the event studies, thus seeking to assess the market reaction following the announcement of the annual earnings during the announcement period. Using the methodology adopted by Beaver (1968), our study attempts to measure the impact of informational accounting result by evaluating the reaction of the market in terms of price change and volume change at the announcement week. In this study, we are interested in companies listed in the Casablanca Stock Exchange for the period [2010-2015]. To our knowledge, it constitutes the first event study in the framework of the announcement of accounting measures.

This paper is organized as follows: section 2 presents the literature review on event studies; section 3 reviews the basics of methodology relating to event study. Section 4 outlines the empirical results obtained for our study. Lastly, Section 5 summarizes our findings.

\section{Literature Review}

The first studies analyzing the reaction of the stock price following the announcement of accounting measures date back to the late sixties, including the famous studies of Beaver (1968) and Ball and Brown (1968). In the same vein, there is also the study of FFJR (1969), which analyzes the market reaction following the announcement of the Split. The authors confirm the presence of a positive market reaction following the announcement of the Split. Kothari and Warner (2007) argue that, despite the difference in their methodology, event studies have been widely applied. The authors report not less than 565 studies published in the five most known journals in finance for the period [1974 to 2000], excluding studies published in magazines and accounting journals. This is also explained by the results achieved by these studies which confirm in their majority the presence of a positive market reaction due to the announcement of accounting results, and consequently the hypothesis of financial market efficiency.

During the past four decades, we have seen the development of three different approaches regarding the extent of the informational impact on the financial market: First, the approach based on the information content 
originally developed by Beaver (1968); Then, the approach based on valuation relevance developed by Ball and Brown (1968) and FFJR (1969) and finally, the approach value relevance or association uses simple long term relationship tests between return, on the one hand, and an accounting variable, on the other hand (Ramesh and Thiagarajan, (1995); Collins et al, (1997), Lev and Zarowin (1999) ...)..

Applying the first two approaches to the same sample of companies for the period [1970-2000], Lo \& Lys (2000a) notice that when the information content remains constant valuation relevance criterion decreases. The authors argue that this outcome difference between the two approaches is probably due to the presence of publications rather than to those publicly revealed (for example, the accompanying notes to the stock options). Unlike association studies using a long-term event window and accusing for unfairness in methodology (Kothari and Warner, (2007)), the information content studies use a short-term window (e.g., 18 weeks) and report in their majority significant results in different countries, for example, studies of Ball and Brown, (1968) in the United States, the study of Brown (1970) in Australia, the study of Firth (1981) in the United Kingdom, and the studies of Haw, Qaqing, and $\mathrm{Wu}(2000)$ and Huang and $\mathrm{Li}$ (2014) in China.

Moreover, several recent studies confirm the increased level of information content of accounting result the last two to three decades in relation to their value relevance, which is usually measured over a wide window and reflected by R2. This calls into question the usefulness of the information content outside reporting period (Kim and Verrecchia, 1991). Additionally, Landsman and Maydew (2002) confirm that the market reaction is particularly stronger for large companies.

Recently, Huang and Li (2014), adopting the approach of Beaver (1968) have carried out a study comparing the behavior of prices and volumes subsequent to the announcement of accounting results in China and the United States. The authors identify a positive reaction during the announcement for both markets. However, the Chinese financial market shows a less intense reaction comparing to US market. According to the authors, this can be explained by the possibility of information leakage before its announcement. In addition, event studies do not take into account the degree of financial markets development, company sizes, or implemented governance mechanisms. These external factors can be, in our view, essential in explaining the behavior of prices and volumes around the announcement dates.

\section{Methodology and Data}

Consistent with methodology developed in Beaver (1968), I examine the information content of earnings announcements by analyzing the price change and the behavior of trading volume around the earnings announcement week.

\subsection{Price Analysis}

To measure the impact of earnings announcements on volatility of stock return, I analyze the abnormal price change in the report period, which is defined as the 17 weeks surrounding the annual earnings announcement week (i.e. 8 weeks before and 8 weeks after the earnings announcement see the timeline below), relative to nonreport period. If earnings announcements have information content in the sense of leading to changes in the equilibrium value of the market price, the magnitude of the price change should also be larger in week 0 .

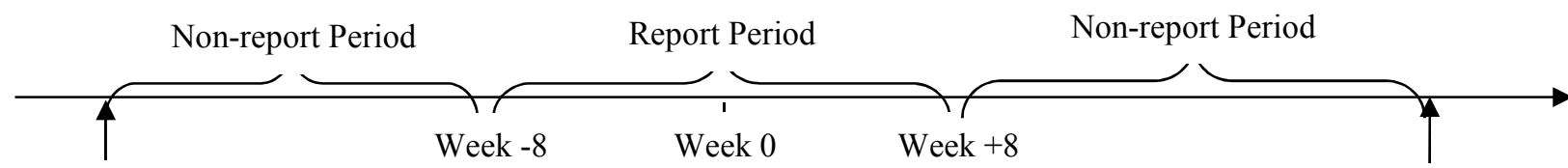

Fiscal year end

Fiscal year end

To find out the abnormal price change in the report period, we eliminate the effect of market-wide events upon the individual stock's price change. We use the following model:

$$
\mathrm{R}_{\mathrm{it}}=\mathrm{a}_{\mathrm{i}}+\mathrm{b}_{\mathrm{i}} \mathrm{Rm}_{\mathrm{t}}+\mathrm{u}_{\mathrm{it}},(1)
$$

Where $R_{i t}$ is the weekly return for firm $i$ in week $t$ and $R_{m t}$ is the weekly market return in week $t$. The residual, uit, represents the part of stock return that could not be explained by the market-wide price movement as reflected in $\mathrm{R}_{\mathrm{mt}}$.

To get estimates of the abnormal price change in the report period, we first estimate model (1) with weekly data from non-report weeks for each firm year. After obtaining the coefficients ait and bit from the non-report periods, these coefficients are applied to the variables in the report period to compute abnormal price change, uit, which cannot be explained by market-wide information.

Following Huang and Li (2014), we don't specify the direction and the magnitude of the prince change in the report period. Therefore, our measure of abnormal return volatility, Uit, is based on the mean of the squared market model adjusted returns, u2it, obtained from model (1) divided by the abnormal return during the nonreport period, $\sigma \mathrm{i} 2$. 


$$
\mathrm{U}_{\mathrm{it}}=\mathrm{u}^{2} \mathrm{it} / \sigma_{\mathrm{i}}^{2}
$$

For each week of the report period, we average Uit over each firm and each week and compare the values in each of the 17 report weeks with the average values from non-report weeks. If earnings reports possess information content, then Uit will be larger than 1.

\subsection{Volume analyze}

The aim objective of volume analysis is to evaluate the impact of earnings announcement on trading volume in report period. To do this, we should remove the effects of market-wide events upon the individual security's volume because it is possible that the abnormally high volume may be caused in part by market-wide pieces information or by another noise causing increases in the volume. The following model was used to abstract from market-wide events:

$$
\mathrm{V}_{\mathrm{it}}=\mathrm{a}_{\mathrm{i}}+\mathrm{b}_{\mathrm{i}} \mathrm{Vm}_{\mathrm{t}}+\varepsilon_{\mathrm{it}}
$$

Where $V_{i t}$ is an average of the daily percentage of shares traded in a week. The number of trading days in the week is used to adjust for the fact that not all weeks have the same number of trading days. Vit is computed as follows:

$$
V_{i t}=\frac{\text { No. of shares of firm traded in week } \mathrm{t}}{\text { No. of shares outstanding for firm in week }} \times \frac{1}{\text { No. of trading days in week }}
$$

$\mathrm{V}_{\mathrm{mt}}$ represents the level of volume for all listed firms; thus $\mathrm{V}_{\mathrm{mt}}$ is defined as follows:

\section{$V_{m t}=\frac{\text { No. of shares traded of all firms in week } \mathrm{t}}{\text { No.of shares outstanding for all firms in week }} \times \frac{1}{\text { No.of trading days in week }}$}

Following Beaver (1968), we estimate model (2) with weekly data from non-report weeks for each firm year to obtain estimates of abnormal trading volume in the report period. Thus, if earnings announcements have information content, the assumptions of the classical regression model are violated during the report period since $\mathrm{E}$ (cit) would not be zero. To compute abnormal trading volume, eit, which represents the part of trading that cannot be explained by market-wide information, we first estimate the coefficients ait and bit from the nonreport period, then, these coefficients are applied to the variables for the report period.

\subsection{Sample and Data}

The study is based upon a sample of annual earnings announcements released by Morrocan's firms listed on the Casablanca Stock Exchange Official List during the period [2010-2015]. All companies listed on the Casablanca Stock Exchange are required to make annual earnings announcements. Usually, these are short versions of the annual report that are made public before the annual report. Data and the date of earnings announcements are directly collected from communication service of Casablanca Stock Exchange. We only include a share firms with available annual earnings announcements in the sample, resulting in an average of 71 firms per year of a total of 425 firms years. Table 1 provides the distribution of our sample firms across years. It reports the number of firm week observations and number of firms by year, resulting in a quasi-constant percentage distribution by year.

Table 1: Sample Distribution

\begin{tabular}{ccccc}
\hline Year & No. of firm-week observations & Percentage & No. Of firms per year & Percentage \\
\hline 2010 & 3432 & $16 \%$ & 66 & $16 \%$ \\
2011 & 3451 & $16 \%$ & 68 & $16 \%$ \\
2012 & 3565 & $17 \%$ & 71 & $17 \%$ \\
2013 & 3735 & $18 \%$ & 72 & $17 \%$ \\
2014 & 3640 & $17 \%$ & 74 & $17 \%$ \\
2015 & 3240 & $15 \%$ & 74 & $17 \%$ \\
Total & 21063 & $100 \%$ & 425 & $100 \%$ \\
\hline
\end{tabular}

The table reports the sample distribution across year for Moroccan listed firms. The sample period is from 2010 to 2015.

The distribution of financial reporting lag appears in table 2. Even if firms are free to choose their fiscal year end, around $96 \%$ of listed firms have their fiscal year end in December. Table 2 also shows that most earnings are released between 6 to 11 weeks after the fiscal year end. In addition, most earnings announcements (around 92\%) are achieved before 3 months after the fiscal year end. Table 3 indicates the descriptive statistics for the main variables used in the tests. Vit has a mean of 0,33.10-3, which is weekly greater with that of $V_{\mathrm{mt}}$ $(0,26 \cdot 10-3)$. The Mean of $R_{i t}$ is $0,8 \cdot 10-4$, indicating an annual return of around $0,4 \%$ which is very low compared to other stock emerging market and confirming the weak contribution of stock market as source of financing in Moroccan economic context. 
Table 2: Number of Weeks between Fiscal Year End and Earnings Announcement Date

\begin{tabular}{cc}
\hline No. of weeks & Percentage of Announcements \\
\hline$<5$ & $1 \%$ \\
5 & $1 \%$ \\
6 & $5 \%$ \\
7 & $5 \%$ \\
8 & $5 \%$ \\
9 & $10 \%$ \\
10 & $20 \%$ \\
11 & $42 \%$ \\
12 & $3 \%$ \\
13 & $2 \%$ \\
14 & $1 \%$ \\
15 & $1 \%$ \\
$>15$ & $4 \%$ \\
\hline
\end{tabular}

This table reports the sample distribution of financial reporting lags

Table 3: Descriptive statistics

\begin{tabular}{ccccc}
\hline Variables & Vit & Vmt & Rit & Rmt \\
\hline Mean & 0,00033 & 0,00026 & 0,00008 & 0,00006 \\
STD & 0,00128 & 0,00021 & 0,00957 & 0,00234 \\
$5 \%$ & 0,00000 & 0,00008 & $-0,01217$ & $-0,00363$ \\
$25 \%$ & 0,00001 & 0,00015 & $-0,00308$ & $-0,00132$ \\
Median & 0,00006 & 0,00021 & 0,00000 & 0,00005 \\
$75 \%$ & 0,00023 & 0,00031 & 0,00306 & 0,00146 \\
$95 \%$ & 0,00134 & 0,00057 & 0,01348 & 0,00374 \\
\hline
\end{tabular}

This table reports the descriptive statistics for the main variables used in the study. Vit is the average of the daily percentage of shares traded for firms $i$ in week $t$. Rit is the weekly return for firm $i$ in week $t$. Rmt is the weekly market return in week t.

\section{Results}

\subsection{Price Analysis}

To confirm the presence of information content of earning around earnings announcement, the magnitude of the price change should be larger in week 0 than during the non report period. Thus, we compare return volatility in the report and non-report periods. Table 4 provides the Fam-Macbeth regression results of model 1. The estimates of ait, bit, uit are obtained from regression with non report period data. While, the explanatory power of market return is closer to $7 \%$, the coefficient bit shows an estimation of 1,0531 which indicates an operational measure of a stock's riskiness.

Table 4: Fama-MacBeth Regression Results for Returns

\begin{tabular}{c|c}
\hline Dependent variable: Rit & Estimates of coefficients \\
\hline Constant & $1,2259^{* * *}$ \\
Rmt & $(0,197)$ \\
& 1,0531 \\
Adjusted R-squared & $(22,891)^{* * *}$ \\
& 0,0699 \\
\hline
\end{tabular}

This table reports the Fama-Macbeth regression results for returns. The dependent variable Rit is the weekly return for firm $\mathrm{i}$ in week $\mathrm{t}$. Rmt is the weekly market return in week t. T-statistics for the time-series averages are presented in the parentheses. $*, * *$, and $* * *$ denote t-statistics are significant at $10 \%, 5 \%$, and $1 \%$ level, respectively.

We use model (1) to compute the residual, uit, for each week $t$ of the report period and for each earnings announcements as follows: uit $=$ Rit - ai - biRmt. To obtain Uit the residual (uit) was squared and divided by abnormal return in the non-report period for each firm $(\sigma i 2)$. Then: Uit $=u 2 i t / \sigma i 2$.Figure 1 describes the behavior of the average of Uit over each firm and each report week. It shows that the magnitude of the price change in week 0 is much larger than its average during the non report period. This result confirms that earnings disclosures bring an abnormal price activity beginning one week before the announcements. In other hands, it supports the results obtained recently in other countries like US and China (Huang and Li, 2014). 
Price residual $\left(\mathrm{U}_{\mathrm{it}}\right)$

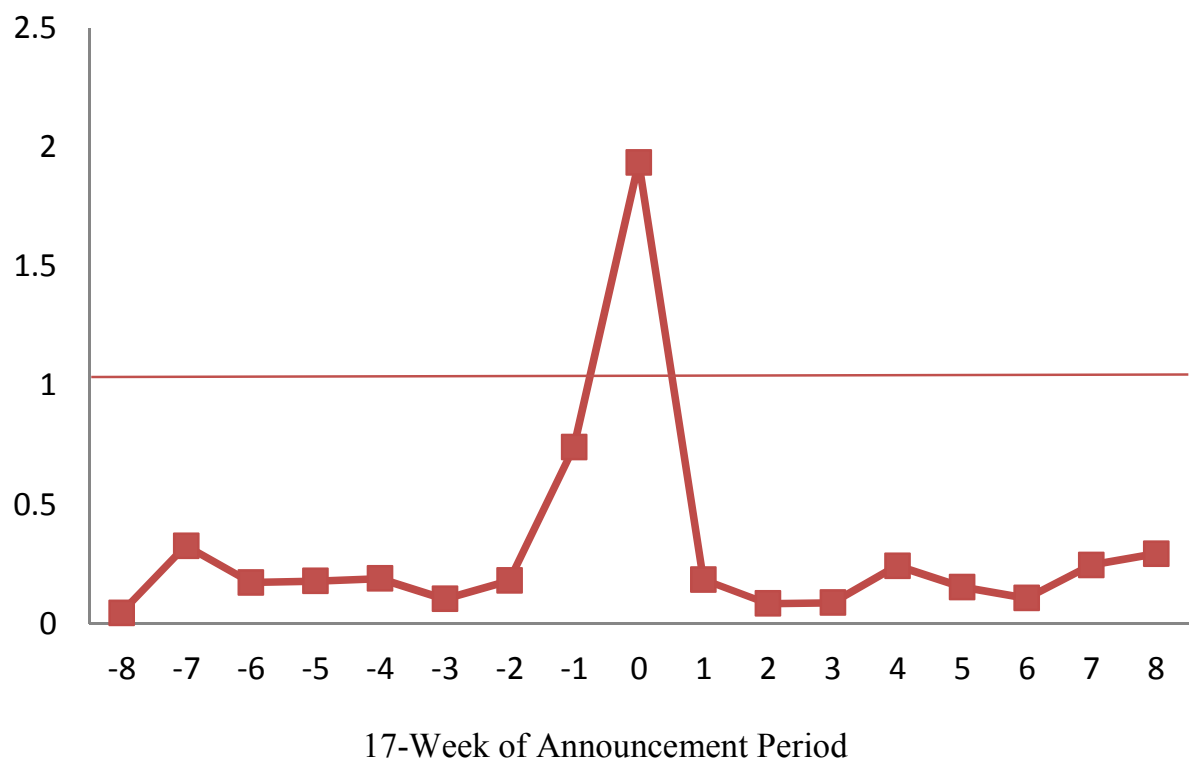

Figure 1 depicts the return volatility changes in the 17 -week report period. The change in return volatility is computed with Uit $=u 2 i t / s 2$ it, where uit is estimated using model (1) Rit $=$ ai + biRmt + uit with data from the non-report period. sit is the abnormal return in the non-report period for firm $i$. The dotted line, which equals 1 , indicates the average price residual in the non-report period.

To support our finding, we also calculate and present the frequency of $U_{\text {it }}$ (figure 2), which is higher than 1 in the report period. The plot shows the frequency of $U_{\text {it }}$ being above 1 , it reaches a peak in week 0 . They are furthers peaks of $U_{i t}$ mainly occur in post announcement weeks. In sum, ours results confirm that relating to mean $U_{i t}$ analysis: there is abnormal price activity at the time of earnings announcement.

Number of $U_{\text {it }}>1$

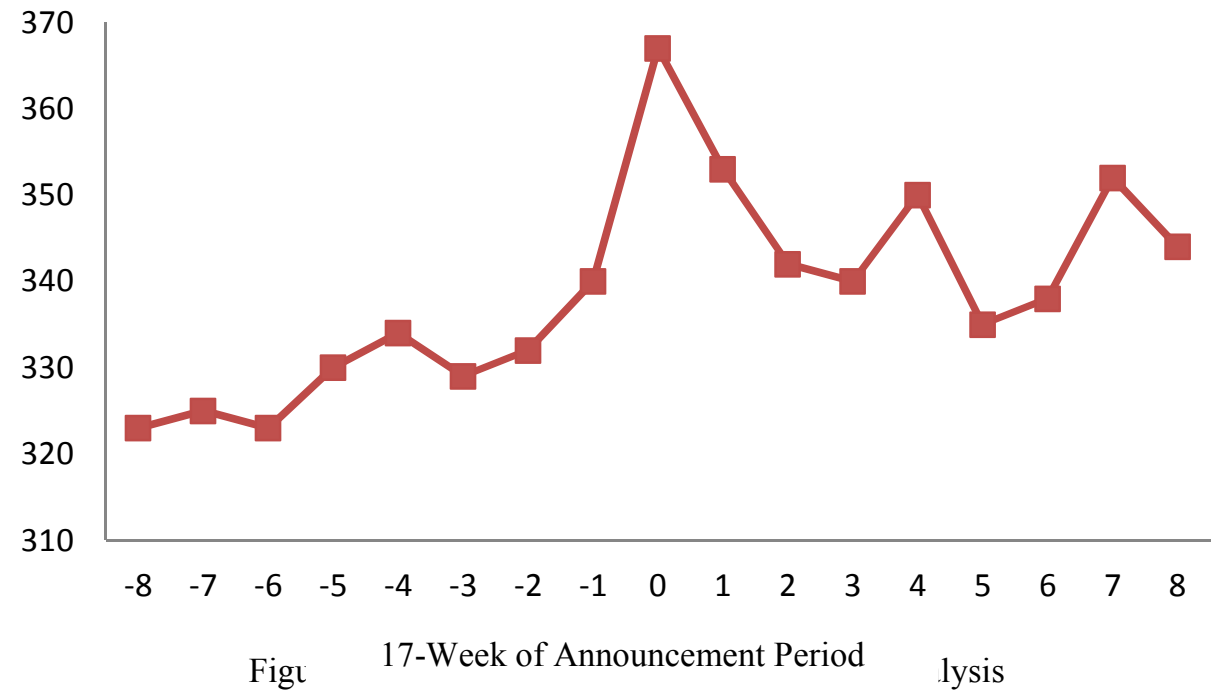

Figure 2 depicts the frequency of $U_{i t}>1$ in the 17 -week report period

\subsection{Volume Analysis}

The estimate of model (2) is based on non report period to obtain the coefficients ait and bit which are applied to the model in report period in order to control for forces that are unrelated to earnings announcements. Then, the model (2) allows to assess the presence or not of abnormal trading volume activity around the earnings announcements. Table 5 shows the Fama-MacBet regression results for model (2). We find that Vmt has less explanatory power, with the adjusted R2 being $2 \%$ compared to that noted in others studies, for example, Huyan and $\mathrm{Li}$ (2014) find a R2 of $6 \%$ for US market and 18\% for Chinese market. 
Table 5, Fama-Macbeth Regression Results for Trading Volume

\begin{tabular}{c|c}
\hline Dependent variable: $\mathrm{V}_{\mathrm{it}}$ & Estimates of coefficients \\
\hline Constant & $0.000101^{* * *}$ \\
$\mathrm{R}_{\mathrm{mt}}$ & $(4.453)$ \\
& 1.684 \\
Adjusted R-squared & $(11.619)^{* * *}$ \\
0.019 \\
\hline
\end{tabular}

The table reports the Fama-Macbeth regression results for trading volume. The dependent variable Vit is the average of the daily percentage of shares traded for firms $i$ in week $t$. Vmt is the average of the daily percentage of shares traded on the market in week t. T-statistics for the time-series averages are presented in parentheses. $*, * *$, and $* * *$ denote $\mathrm{t}$-statistics are significant at the $10 \%, 5 \%$, and $1 \%$ level, respectively.

To examine the trading volume activity around the earnings announcement, we first calculate the raw trading volume and the abnormal trading volume for each week during the report period. Then, we plot the timeseries average of the cross-sectional mean trading volume over the 17 week report period. The figure 3 illustrates that in the weeks immediately prior to the announcement; the trading volume is below the normal level (the mean trading volume in the non-report period) and it starts to climb up from the announcement week to reach the peak level one week after. Our evidence is different to that obtained in others studies (Beaver, 1968; Landsman \& Maydew; 2002, Huang \& Li 2014) suggesting the specificity of financial market and the investors behaviors in developing and emerging countries. This result confirms that not all investors may trade instantly upon the announcement of annual earnings but their trades persist for one week later.

Trading Volume $\left(\mathrm{V}_{\mathrm{it}}\right)$

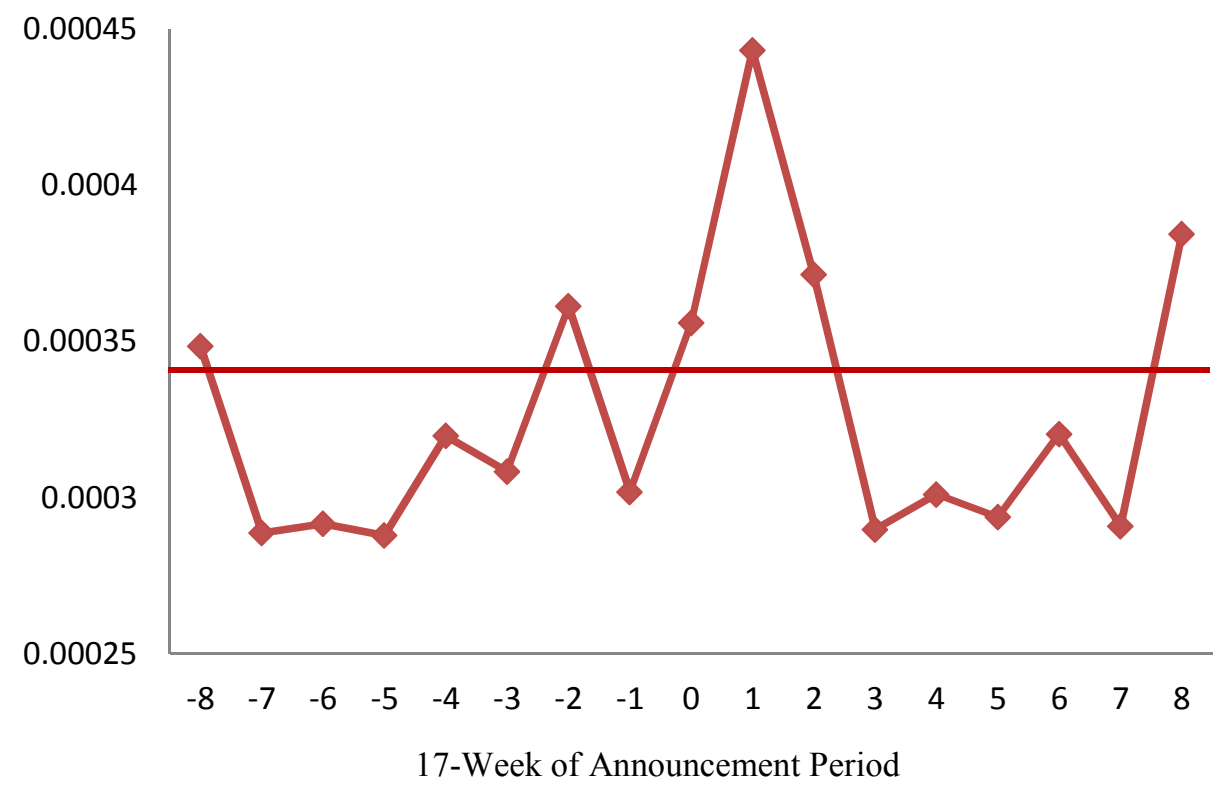

Figure 3, Volume Analysis

Figure 3 depicts the time-series average of cross-sectional mean trading volumes over the 17-week report period. Trading volume Vit is the average of the daily percentage of shares traded for firm $i$ in week t. The dotted line indicates the mean trading volume in the non-report period.

Thereafter, we complete our analysis by computing the mean abnormal trading volumes, cit, (figure 4) using data from non report period to removing the impact from market-wide effects. The main result is that trading volumes, eit, show a similar pattern to that of raw trading volumes. Therefore, the abnormal trading volumes reach the peak level with a lag of one week and return to his normal level from week 2. 


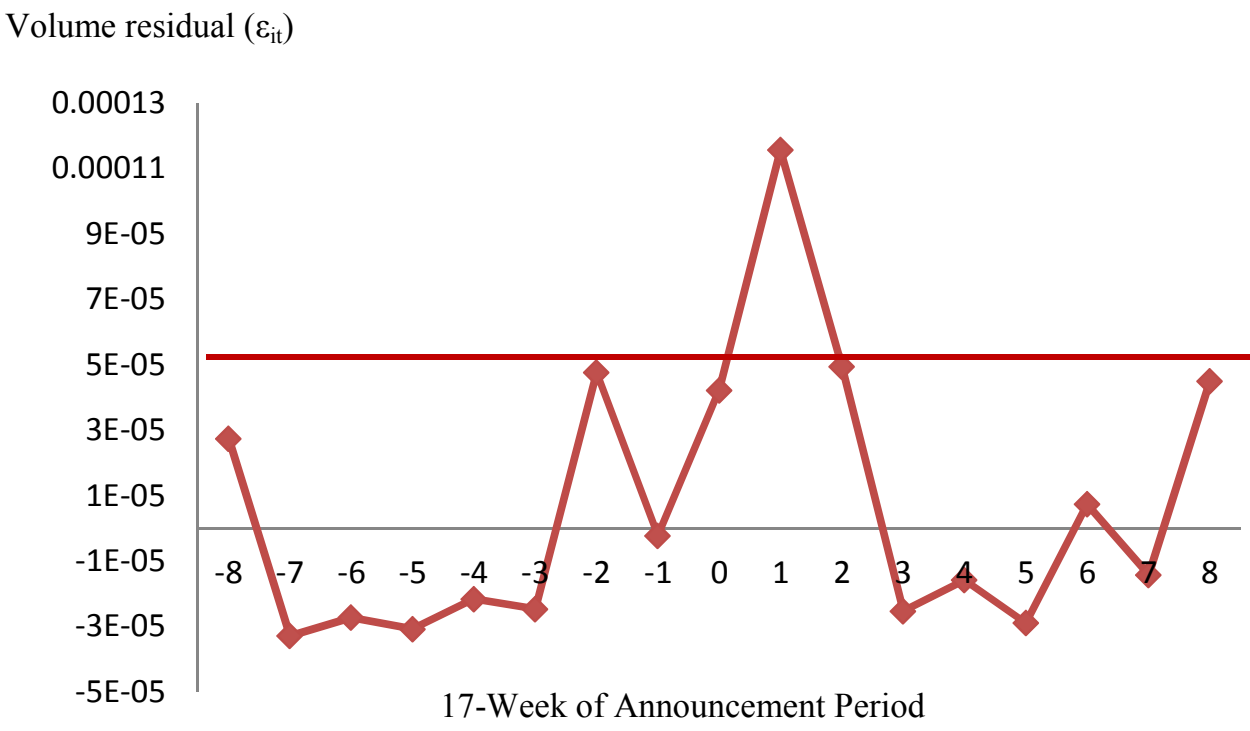

Figure 4, Volume Residual Analysis

Figure 4 depicts the time-series average of cross-sectional mean abnormal trading volumes over the 17week report period. The abnormal trading volume eit is calculated using model (2) Vit $=$ ait $+b i t V m t+\varepsilon i t$ with data from the non-report period. The dotted line indicates the mean abnormal trading volume in the non-report period.

The similar pattern is also shown (figure 5) when we compute the frequency of positive abnormal trading volume in each report period week. The usefulness of frequency analyze is to eliminate the concern that our finding are driven by a few dominant observations. Then, the frequency exponentially climbs up in week 0 to reach the peak in week 1 supporting the result obtained for the mean abnormal trading volumes noted in figure 4 and going back to his normal level in week 2.

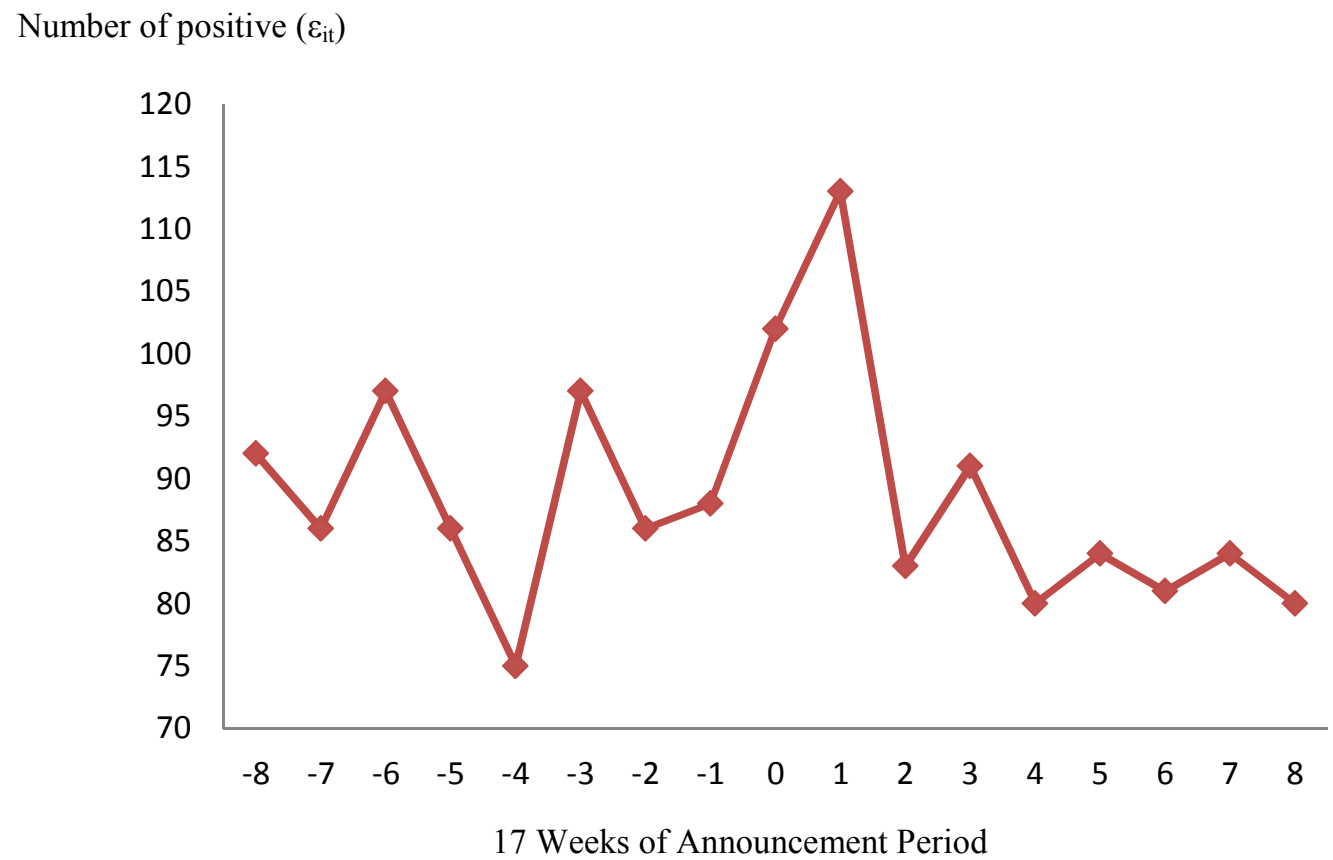

Figure 5, Frequency of positive eit's -Volume Residual Analysis-

Figure (5) depicts the frequency of positive abnormal trading volumes in the 17-week report period.

\section{Conclusion}

Our study fits into field of information content studies that are largely applied in different stock markets worldwide. In our knowledge, it's the first event study that is achieved in Moroccan Stock Market. The main 
objective of this work is to determine the presence of abnormal trading volume and volatility around the earnings announcements and then confirm the efficiency hypothesis as defended by Fama (1970) in his semi strong form. The result shows the presence of information content of earnings around the reporting period, in terms of abnormal trading volume and price change. However, the volume change shows a one week lag comparing to the price change which depicts a high volatility in earnings announcement week. This result can pave the way for the future researches to determine the specificities of Moroccan Stock Market, to analyze the investor's behaviors in emerging and developing countries because the similar result are observed in China case (Huang \& Li, 2014). Further, our study sketches a future studies to be interested by the impact of financial and accounting announcement, the relation between mandatory and voluntary reporting and return of the firm especially in Moroccan Stock Exchange which is characterized by his weak role to attract investors and to fund firms.

\section{References}

Ball, R., and Brown, P. (1968). "An empirical evaluation of accounting income numbers". Journal of Accounting Research, 6, 159-178.

Beaver, W. (1968). "The Information Content of Annual Earnings Announcements", Journal of Accounting Research, 6, 67-92.

Brown, P., (1970). "The impact of the annual net profit report on the stock market". The Australian Accountant, 277-283.

Collins, D., Pincus, M., and Xie, H. (1997). "Equity valuation and negative earnings: The role of book value of equity". Working paper, University of Iowa, Iowa City, IA.

Dolley, J. C. (1933). "Common stock split-ups motives and effects". Harvard Business Review, 12(1), 70-81.

Francis, J., Schipper, K., and Vincent, L. (2002). "Expanding Disclosures and the Increased Usefulness of Earnings Announcements", The Accounting Review, 77(3), 515-546.

Fama, E. F. (1970). Efficient capital markets: a review of theory and empirical work. Journal of Finance, 25(2), 383-417.

Fama, E. F., Fisher, L., Jensen, M. C., \& Roll, R. (1969). "The adjustment of stock prices to new information". International Economic Review, 10(1), 1-21.

Fama, E. F., \& MacBeth, J. (1973). "Risk, return and equilibrium: empirical tests". Journal of Political Economy, 81, 607-636.

Firth, M., (1981). "The relative information content of the release of financial results data by firms". Journal of Accounting Research, 19, 521-529.

Haw, I., Qaqing, D., Wu. W., (2000). "Timeliness of annual report releases and market reaction to earnings announcements in an emerging capital market: The case of China". Journal of International Financial Management and Accounting, 11, 108-131.

Huang, Y. and Li, X. (2014). "Information Content of Annual Earnings Annoucements : A Comparative Study". China Accounting and Finance Review, 11(2), 171-182.

Kim, O., Verrecchia, R.E., (1991). "Market reaction to anticipated announcements". Journal of Financial Economics, 30, 273-309.

Kothari, S. P., \& Warner, J. B. (2007). "Econometrics of event studies". In B. Espen Eckbo (Ed.), Handbooks in finance series: Vol. 1. Handbook of corporate finance: Empirical corporate finance. North-Holland: Elsevier.

Landsman, W. and Maydew, E. (2002). "Has the Information Content of Quarterly Earnings Announcements Declined in the Past Three Decades?", Journal of Accounting Research, 40 (3), 797-808.

Lev, B., and Zarowin, P. (1999). "The boundaries of financial reporting and how to extend them". Journal of Accounting Research, 37, 353-385.

Lo, K and Lys, T. (2000). "Bridging the gap between value relevance and information content". Working paper, University of British Columbia.

MacKinlay, A. C. (1997). "Event studies in economics and finance". Journal of Economic Literature, 35, 13-39.

Ramesh, K., and Thiagarajan, R. (1995). "Inter-temporal decline in earnings response coefficients". Working paper. Northwestern University, Evanston, IL. 